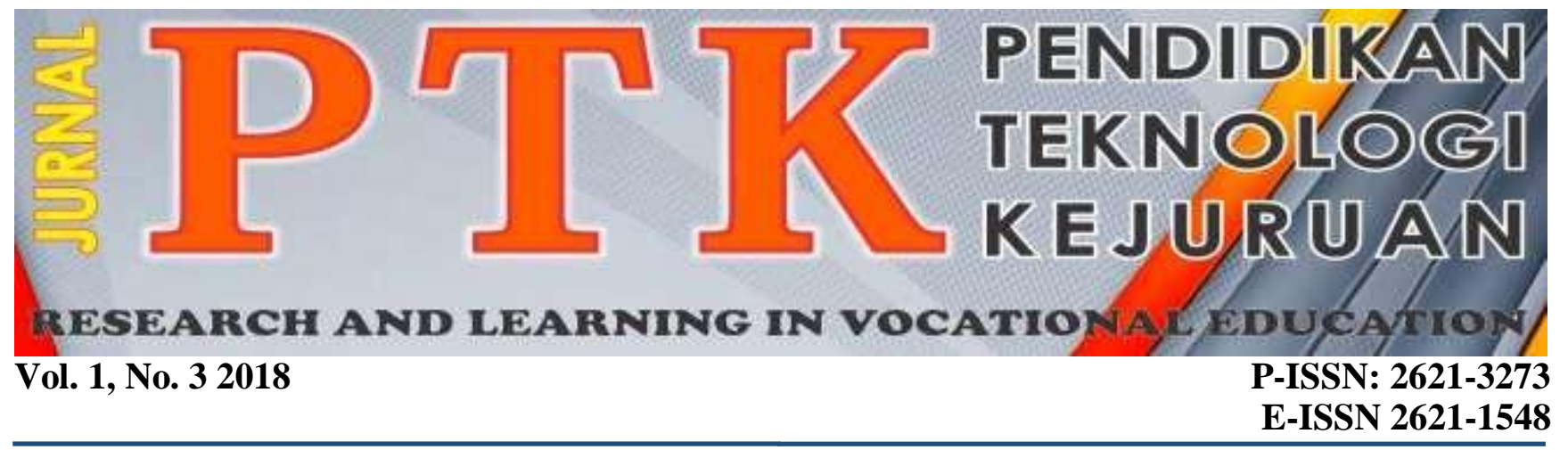

\title{
ANALISIS NILAI KALORI BRIKET TEMPURUNG KELAPA SEBAGAI BAHAN BAKAR ALTERNATIF DI KECAMATAN SIPORA UTARA KABUPATEN MENTAWAI
}

\author{
Yaumal Arbi ${ }^{1}$, Eka Rahmatul Aidha ${ }^{2}$, Linda Deflianti ${ }^{3}$ \\ Sekolah Tinggi Teknologi Industri (STTIND) Padang \\ *Corresponding author, e-mail: yaumalarbi@gmail.com
}

\begin{abstract}
Abstrak--Sebagai daerah kepulauan, sebagian besar pesisir pantai Mentawai ditumbuhi oleh pohon kelapa. Menurut data dari pemerintahan daerah Mentawai tahun 2017, luas perkebunan tanaman kelapa di Mentawai adalah sebesar 7.910,75 ha dengan jumlah produksi 7.634 ton. Kelapa yang dihasilkan diolah menjadi kopra dan sebagian digunakan untuk konsumsi rumah tangga, limbah tempurung yang dihasilkan biasanya ditinggal begitu saja dan sampah rumah tangga dibuang ke laut, sehingga merusak perairan kelautan. Salah satu upaya yang bisa dilakukan untuk pengolahan limbah ini adalah mengelolanya menjadi briket. Briket dapat dijadikan sebagai bahan bakar alternatif, dengan hal ini permasalahan kelangkaan bahan bakar yang selama ini terjadi, bisa sedikit teratasi. Briket yang dibuat dari limbah tempurung kelapa memiliki nilai kalori yang tinggi. Hasil penelitian yang didapatkan dengan menggunakan bom calorimeter nilai kalori briket 6.304,06 Kal/g dan minyak tanah 11.039,5 Kal/g. Pada percobaan yang dilakukan di lapangan $1 \mathrm{~kg}$ briket bisa mendidihkan $\pm 33 \mathrm{~L}$ air dengan biaya Rp 50/L air sedangkan $1 \mathrm{~L}$ minyak tanah bisa mendidihkan $\pm 47 \mathrm{~L}$ air dengan biaya Rp 212,76/L air. Walaupun nilai kalori minyak tanah lebih tinggi briket tetapi dari segi harga dan ketersediaan bahan baku briket lebih ekonomis daripada minyak tanah. Apabila penggunaan briket diaplikasikan ke masyarakat maka banyak masalah yang teratasi seperti permaslahan sampah dan kelangkaan bahan bakar yang sering terjadi di kepulauan Mentawai.
\end{abstract}

Kata Kunci : Bahan bakar, Kalori, Sampah, Tempurung kelapa

\begin{abstract}
As an archipelago, most of the Mentawai coastline is overgrown with coconut trees. According to data from the Mentawai regional government in 2017, the area of coconut plantations in Mentawai is 7,910.75 ha with a total production of 7,634 tons. The resulting coconut is processed into copra and part of it is used for household consumption, the resulting shell waste is usually left behind and household waste is discharged into the sea, thus damaging the marine waters. One effort that can be done to treat this waste is to manage it into briquettes. Briquettes can be used as alternative fuels, in this case the problem of fuel scarcity that has been happening so far can be overcome. Briquettes made from coconut shell waste have a high calorific value. The results obtained by using calorimeter bombs calorie value of briquettes 6,304,06 Kal / g and kerosene 11,039,5 Kal / g. In experiments carried out in the field of $1 \mathrm{~kg}$ of briquettes can boil \pm 33 L of water at a cost of Rp 50 / L of water while 1 L of kerosene can boil \pm 47 L of water at a cost of Rp 212.76 / L of water. Although the calorific value of kerosene is higher in briquettes but in terms of price and availability of raw materials, briquettes are more economical than kerosene. If the use of briquettes is applied to the community, there are many problems that are overcome such as garbage problems and fuel scarcity that often occur in the Mentawai islands.
\end{abstract}

Keywords: Fuel, Calories, Trash, Coconut Shell 


\section{PENDAhULUAN}

Tempurung kelapa merupakan sumber energi alternatif yang melimpah dengan kandungan energi yang relatif besar, bahan bakunya mudah didapatkan dan dapat digunakan oleh masyarakat tanpa mengeluarkan biaya yang besar. Tempurung kelapa dapat digunakan sebagai bahan bakar yang lebih ramah lingkungan. Tempurung kelapa digunakan sebagai bahan bakar pada rumah tangga. Penggunaan tempurung kelapa sebagai bahan bakar langsung kurang praktis, karena menghasilkan asap yang banyak, karena itu harus diolah terlebih dahulu menjadi briket (Arni, Labania, \& Nismayanti, 2014).

Kondisi geografis wilayah kepulauan Mentawai yang berupa yang jauh dari ibu kota Provinsi menyebabkan biaya transportasi menjadi besar. Sebagian besar kebutuhan pokok masih di datangkan dari luar daerah, hal ini menyebabkan harga-harga menjadi jauh lebih mahal bahkan sampai dua kali lipat dari harga aslinya. Demikian juga dengan bahan bakar minyak. Selain harga yang mahal, bahan bakar di sini juga kadang sering terjadi kelangkaan, terutama pada cuaca buruk. Pada umumnya Kabupaten Kepulauan Mentawai ditumbuhi oleh tanaman Kelapa karena merupakan daerah kepulauan terutama di daerah pesisir pantai.

Kelapa menjadi salah satu komoditi yang di unggulkan selain cengkeh, baik di olah menjadi kopra maupun di jual mentah sebagai kelapa bulat. Berdasarkan informasi yang dihimpun dari Kantor Perkebunan Kabupaten Kepulauan Mentawai yang terangkum dalam Buku Mentawai Dalam Angka Tahun 2017 diperoleh data mengenai luas tanaman kelapa di Kabupaten Kepulauan Mentawai adalah sebesar 7.910,75 ha dengan luas produksi sebesar 7494,00 ha dan jumlah produksi 7634,00 ton. Limbah tempurung kelapa yang di hasilkan di tinggalkan begitu saja di kebun ataupun di buang ke laut dan sekitar pantai sehingga merusak estetika lingkungan dan mencemari perairan kelautan. Hal ini terjadi karena kurangnya kesadaran masyarakat akan dampak negatif yang akan ditimbulkan. Salah satu cara yang paling efektif dalam penanggulangan masalah sampah ini adalah mereduksi limbah tempurung kelapa dari sumbernya (Sari, 2016). Limbah tempurung kelapa dapat diolah menjadi briket tempurung kelapa yang dapat dijadikan sebagai bahan bakar memasak.

Harga bahan bakar yang mahal di Kabupaten Kepulauan Mentawai yang mahal membuat masyarakat mengeluh. Selain itu, langkanya bahan bakar juga menjadi permasalahan di Kabupaten Kepulauan Mentawai. Maka dari itu perlu dilakukan upaya yang sistematis untuk menerapkan berbagai alternatif energi yang layak bagi masyarakat

[1]

\section{METODE}

\section{Tempat Penelitian}

1. Kabupaten Kepulauan Mentawai

Lokasi penelitian dilakukan di Desa Bukit Pamewa Kecamatan Sipora Utara Kabupaten Kepulauan Mentawai.Lokasi penelitian dapat dilihat pada gambar 1.

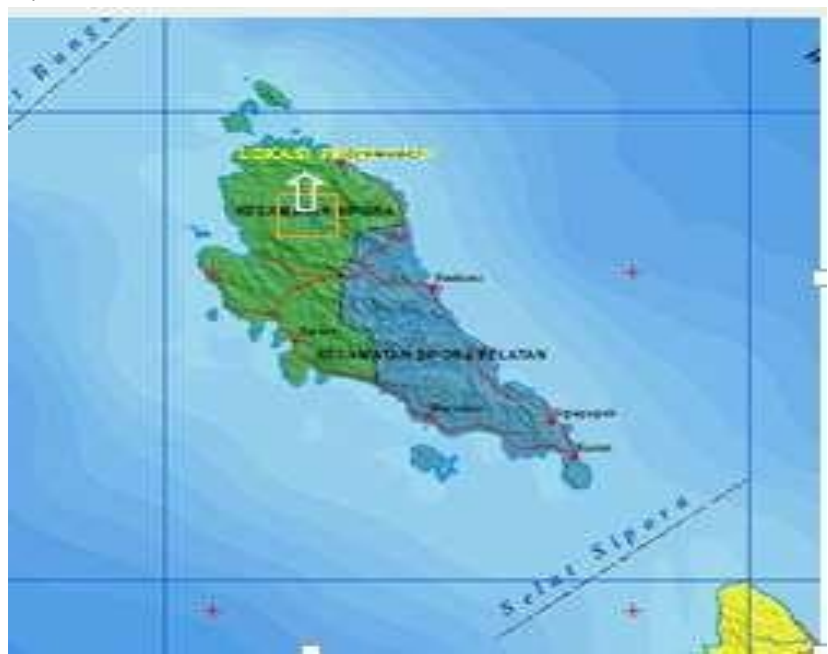

Gambar 1. Lokasi Penelitian

\section{Laboratorium Kimia STTIND}

Penelitian pengujian nilai kalori ini dilakukan di Laboratorium kimia STTIND Padang. Sampel yang digunakan adalah briket tempurung kelapa dan minyak tanah.Pengujian nilai kalori ini menggunakan Bomb Calorimeter. Bom kalorimeter ini digunakan untuk menghitung nilai kalori briket tempurung kelapa dan minyak tanah yang tepat, teliti dan sesuai dengan standar yang sudah ditentukan. Penelitian ini hanya menghitung nilai kalori dengan sampel yang sudah disediakan.

\section{Data}

Data yang diperlukan pada penelitian ini sebagai beikut :

1. Data primer pada penelitian ini adalah

a) Biaya yang dikeluarkan dalam pembuatan briket dan pembelian minyak tanah

b) Nilai kalori briket tempurung kelapa dan minyak tanah

c) Hasil pengujian nilai kalori briket tempurung kelapa dan minyak tanah yang dikeluarkan oleh Laboratorium.

2. Data Sekunder, data sekunder pada penelitian ini adalah :

a) Harga jual briket tempurung kelapa dan minyak tanah 
b) Nilai kalori briket tempurung kelapa dan minyak tanah

c) SNI 01-6235-2000 ( Nilai Kolori briket arang)

\section{Prosedur Penelitian}

Alat dan Bahan

1. Alat

Alat yang dibutuhkan dalam penelitian ini adalah sebagai berikut :

1) Tempat pengarangan

2) Lumpang dan alu

3) Ayakan

4) Timbangan

5) Alat cetakan briket

6) Kompor briket

7) Kompor minyak tanah

8) Termometer

9) Wadah pemanas air

10) Stopwath dan kamera

2. Bahan

Bahan yang digunakan dalam penelitian ini adalah sebagai berikut :

1) Tepung kanji (amilum)

2) Korek api

3) Briket tempurung kelapa

4) Minyak tanah

5) Air

\section{Cara Kerja Pembuatan Briket Tempurung Kelapa}

1. Prosedur Pembuatan Larutan Kanji

a) Timbang tepung kanji sebanyak 30 gram

b) Tambahkan air secukupnya sampai tepung kanji larut

c) Panaskan air hingga mendidih

d) Masukkan tepung kanji yang sudah dilarutkan ke dalam air mendidih sambil diaduk-aduk (agar tidak mengumpal).

2. Prosedur Pembuatan Briket Tempurung Kelapa

a) Bahan baku dalam keadaan kering dan siap dikarbonisasi.

b) Lakukan pembakaran di dalam drum (pembakaraan dilakukan tidak sampai menjadi abu)

c) Tempurung yang sudah terbakar semua, drum ditutup menggunakan karung goni basah dan dilengkapi dengan tutup drum (Penutupan dilakukan untuk menghilangkan $\mathrm{O}_{2}$ )

d) Setelah ditutup beberapa jam keringkan arang tempurung

e) Arang tempurung yang sudah dikeringkan, dihaluskan dengan cara penumbukkan f) Setelah dilakukan penumbukkan, arang tempurung diayak untuk mendapatkan ukuran partikel yang lebih halus

g) Campurkan larutan kanji pada arang tempurung yang telah diayak perlahan-lahan sambil diaduk agar proses pengeleman merata

h) Cetak arang tempurung kelapa menggunakan alat yang sudah disediakan

i) Briket yang telah jadi, dijemur samapi kering

j) Briket arang tempurung kelapa siap untuk digunakan

3. Bomb Calorimeter

Alat yang digunakan untuk bomb calorimeter

a) Timbangan analitik

b) Timbangan, minimum $3000 \mathrm{~g}$

c) Gelas ukur, $1000 \mathrm{ml}$

d) Stopwatch

e) Kompor

f) Unit bomb calorimeter

g) Thermometer

h) Alat pengukur panjang

i) Bomb beserta cawan

j) Tabung oksigen

k) Gelas piala

Cara kerja :

a) Pasang cawan yang telah diisi sampel (pellet) pada tempatnya dan atur kawat pijar sedemikian rupa sehingga menyentuh sampel.

b) Pipet $1 \mathrm{ml}$ aquadest dengan pipet volume, masukkan ke dalam bomb.

c) Pasang tempat cawan pada bomb, keraskan dengan tutup baut sebaik-baiknya.

d) Isi bomb dengan oksigen, tekanan 35 atm.

e) Pasang bucket yang telah diisi aquadest pada tempatnya.

f) Ambil bomb dengan penjepit dalam keadaan tetap tegak agar sampel tidak berubah posisi.

g) Diatur sambungan mur pada tempatnya dan masukkan bomb pada bucket.

h) Ambil penjepitnya

i) Pasang penutup bak bomb calorimeter pada tempatnya.

j) Hubungkan pengaduk aquadest dengan dinamo (pasang gelang karetnya).

k) Hubungkan dinamo dengan sumber listriknya.

1) Diperiksa temperatur aquadest $\left(1,5{ }^{\circ} \mathrm{C}\right.$ di bawah suhu kamar).

m) Hidupkan alat selama 5, catat nilai kalori yang dihasilkan. 


\section{HASIL DAN PEMBAHASAN}

\section{Hasil}

Hasil percobaan dari pembakaran briket tempurung kelapa dan minyak tanah secara keseluruhan dapat dilihat pada tabel 1:

Tabel 1. Hasil Uji Bahan Bakar

\begin{tabular}{clcc}
\hline No & $\begin{array}{l}\text { Parameter } \\
\text { Uji }\end{array}$ & Briket & $\begin{array}{c}\text { Bahan Bakar } \\
\text { Minyak } \\
\text { Tanah }\end{array}$ \\
\hline 1 & $\begin{array}{l}\text { Nilai Kalori } \\
\text { (Kal) } \\
\text { Waktu }\end{array}$ & 2.048 & $3.193,75$ \\
2 & $\begin{array}{l}\text { Pembakara } \\
\text { n (menit) } \\
\text { Banyak Air } \\
\text { yang } \\
\text { didihkan } \\
\text { L/kg }\end{array}$ & 200 & 199 \\
4. & Biaya \\
Rp/kg/L & 1.650 & 10.000 \\
\hline
\end{tabular}

Dari tabel 1 nilai kalori pada briket tempurung kelapa yang didapatkan pada saat pembakaran adalah $2.048 \mathrm{Kal} / \mathrm{g}$, waktu yang dibutuhkan untuk menghabiskan $1 \mathrm{~kg}$ briket tempurung kelapa selama 3 jam 20 menit dengan jumlah air yang didihkan sebanyak 33 liter dengan biaya Rp 1650. Sedangkan nilai kalori yang didapatkan dari pembakaran 1 liter minyak tanah sebesar 3.193,75 Kal/g, waktu pembakaran minyak tanah hampir sama dengan briket tempurung kelapa yaitu selama 3 jam 19 menit dengan jumlah air yang didihkan sebenyak 47 liter dengan biaya $\mathrm{Rp} 10.000$.

\section{Analisis Hasil}

Pembuatan Briket Tempurung Kelapa

Dari percobaan yang dilakukan menbuat briket tempurung kelapa sangat mudah sehingga bisa dilakukan oleh setiap rumah tangga atau usaha kecil menengah. Hal yang perlu diperhatikan adalah :

1) Pada saat pembakaran tutup drum segera mungkin dengan menggunakan karung goni basah sehingga tempurung tidak menjadi abu.

2) Pemakaian bahan perekat hanya sampai adonan bisa dikepal, sehingga briket yang dihasilkan tidak terlalu lembab agar kandungan air tidak terlalu tinggi yang menyebabkan penjemuran terlalu lama.

3) Lama penjemuran briket berkisar \pm 2 hari di bawah terik sinar matahari.

\section{Nilai Kalori}

Perbandingan nilai kalori yang didapatkan dapat dilihat pada gambar 2 berikut

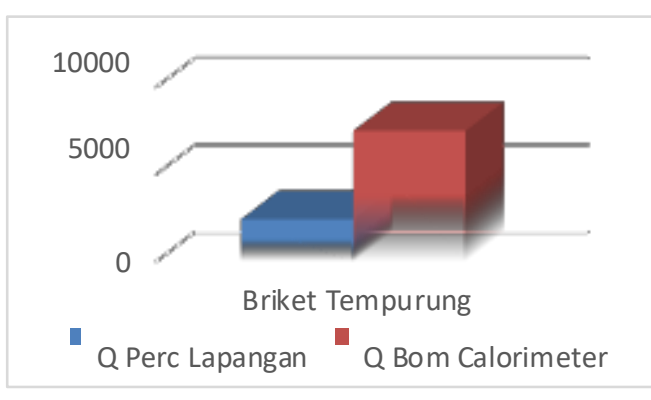

Gambar 2. Perbandingan nilai kalori

Nilai kalori briket tempurung kelapa yang diuji di lapangan memiliki kadar air yang tinggi, penggunaan kompor briket yang terlalu besar, jauh dari wadah yang dipanaskan dan panas yang lepas

hal ini menyebabkan nilai kalori briket tempurung kelapa menjadi sangat rendah bahkan jauh dari standar yang sudah ditentukan. Setelah dilakukan dengan menggunakan alat bomb calorimeter nilai kalori briket tempurung kelapa cukup tinggi bahkan sampai $7.486,5 \mathrm{Kal} / \mathrm{g}$. Nilai kalori yang dihasilkan dari percobaan lapangan hanya 3.193,75 Kal/g. Dari hasil percobaan menggunakan bomb calorimeter dapat dilihat bahwa nilai kalori briket tempurung kelapa yang dibuat secara manual memiliki nilai kalori sesuai dengan SNI 01-6235-2000 yaitu 7.486,51 dengan kadar air $0 \%$.

\section{KESIMPULAN}

Dari penelitian yang telah dilaksanakan dapat disimpulkan sebagai bahwa Nilai kalori briket tempurung kelapa menggunakan alat bomb calorimeter $7.486 \mathrm{Kal} / \mathrm{g}$ dengan kadar air 0\%, nilai ini sesuai dengan standar SNI01-6235-2000 yang mensyaratkan min $5000 \mathrm{Kal} / \mathrm{g}$ untuk briket arang.

\section{DAfTAR Pustaka}

[1] Arni, Labania, H. M., \& Nismayanti, A. (2014). Studi Uji Karakteristik Fisis Briket Bioarang sebagai Sumber Energi Alternatif. Online Jurnal of Natural Science, 3(March), 89-98.

[2] Sari, P. N. (2016). Analisis pengelolaan sampah padat di kecamatan banuhampu kabupaten agam, 157-165.

[3] Sarwono.Studi Ekperimental Karakteristik Briket Organik Dengan Bahan Baku PPLH Seloliman.2015. Jurusan Fisika FTI ITS. Surabaya.

[4] Setiawan, Agung. Pengaruh Komposisi 
Pembuatan Briket Dari Campuran Kulit Kacang dan Serbuk Gergaji Terhadap Nilai Pembakaran. Jurusan Teknik Kimia Fakultas Teknik Universitas Sriwijaya.

[5] Peraturan Pemerintah Nomor 81 Tahun 2012 Tentang pengelolaan sampah Rumah Tangga Dan Sampah Sejenis Sampah Rumah Tangga.

[6] Undang- Undang Nomor 18 Tahun 2008 Tentang Pengelolaan Sampah

[7] A. R. Zumaro and Y. Arbi, "PERANCANGAN REAKTOR BIOGAS DI UPTD PASAR TERNAK PALANGKI," SAINS DAN Teknol. STTIND PADANG, vol. 17, no. 1, pp. 14-19, 2017. 